\title{
A Rare Case Report: Traumatic Isolated Medial Rectus Dehiscence and its Surgical Outcome
}

\author{
Amol T1*, Anshika $\mathrm{S}^{2}$ and Rekha $\mathrm{K}^{3}$ \\ ${ }^{1}$ Consultant Paediatric Ophthalmologist, NKP Salve Institute of Medical Sciences, \\ India \\ ${ }^{2}$ Resident doctor, NKP Salve Institute of Medical science, India \\ ${ }^{3}$ Head of department and Professor, Department of Ophthalmology, NKP Salve \\ Institute of Medical Sciences, India
}

\section{Case Report}

Volume 4 Issue 2

Received Date: February 28, 2019

Published Date: April 05, 2019

DOI: $10.23880 /$ oajo-16000178

*Corresponding author: Amol Tamhane, Consultant Paediatric Ophthalmologist, NKP Salve Institute of Medical Sciences, Digdoh Hills, Hingna Road, Nagpur 440019, Maharashtra, India, Tel: 9930311566; Email: divanshika@gmail.com

\section{Abstract}

Accidental blunt trauma with stick while working at farm or in cases of interpersonal fights a softball injury to eye; all might send the patient to trauma centre with orbital or ocular trauma. Patients with orbital or ocular trauma present with pain in and around the orbit, bruising and swelling causing diplopia and gaze disturbances. The ocular or orbital trauma causing strabismus could be the result of localized acute soft tissue swelling or following orbital fractures, partial or complete loss of extraocular muscle (EOM) and/or cranial nerve function, or mechanical restriction due to damage to surrounding tissues.

Keywords: Strabismus; Blunt Ocular Trauma; Extraocular Muscle Trauma; Ocular Trauma; Orbital Trauma; Medial Rectus Dehiscence

\section{Introduction}

The strabismus following blunt trauma results in an incomitant type which if not impossible, is often difficult to manage. The diplopia caused makes individual's ability to function in day to day tasks difficult. There could be varied aetiologies responsible for strabismus due to ocular or orbital trauma and each require its own indivisualised treatment plan. The signs and symptoms can vary from being quite dramatic to subtle and presenting the examiner with unique challenges.
Appropriate diagnosis of the type and severity of the injury and differentiation between mechanical and neurological involvement is critical in planning the optimal approach for management.

The pre-operative evaluation to assess degree of limitation, muscle function and extent of surrounding tissue damage is done. Further radiological investigations like computed tomography and magnetic resonance imaging required determining the extent of extraocular muscle or bony damage as well as muscle contractility. 


\section{Case Report}

A 35 years old female, farmer by occupation presented in ophthalmology OPD with history of uniocular diplopia and lateral deviation of left eye of 2 days duration. Patient had history of spectacle use since 3 years. There was history of accidental blunt trauma with bamboo stick which snapped on the left eye while working at her farm 2 days back. On examination she had left eye exotropia of about 45 degrees on primary gaze with partially detached tendinious end of the medial rectus muscle seen with conjunctival tissue loss. Extraocular muscle movements were completely restricted on left eye adduction. Her visual acuity was OD 20/20 (aided) and OU 20/70 (unaided; aided visual acuity could not be assessed due to diplopia). There were no associated injuries to the lids; cornea was clear and pupils reacting to light. Fundus examination was within normal limits and Left eye Intraocular pressure was also normal (14mmhg). Diagnosis of Left eye traumatic Medial rectus partial dehiscence was made.

Computed tomography and magnetic resonance imaging to look for lost medial rectus belly was done and
Left orbit exploration and medial rectus muscle repair was planned. Computed tomography scan of left orbit showed intact globe and ruled out any evidence of foreign body. Magnetic resonance imaging showed hyper intense left medial rectus belly suggestive of inflammatory state.

On Left orbit exploration, $3 / 4^{\text {th }}$ medial rectuis muscle rupture around 6-7 $\mathrm{mm}$ posterior to the insertion line identified; $1 / 4^{\text {th }}$ of the muscle was intact which made it easier to hook the muscle and regain it back. 6-0 vicryl suture was passed through the distal stump, initially muscle to muscle approximation was tried but it lead to laxity of the muscle resulting in residual exotropia, hence about 7-8 $\mathrm{mm}$ resection of the intervening proximal muscle stump was done and the distal stump of the muscle was re-inserted in the original insertion line and the conjuntival tear approximated. Patient was assessed on days $0,1,3,7$ and 30 postoperative. There was no diplopia and on Hirschberg's test, revealed acceptable (approximate) 7 degrees exotropia left eye with full and free ocular movements in all gazes. On follow up after 2 months, there was no residual exotropia with full range extraocular movements.

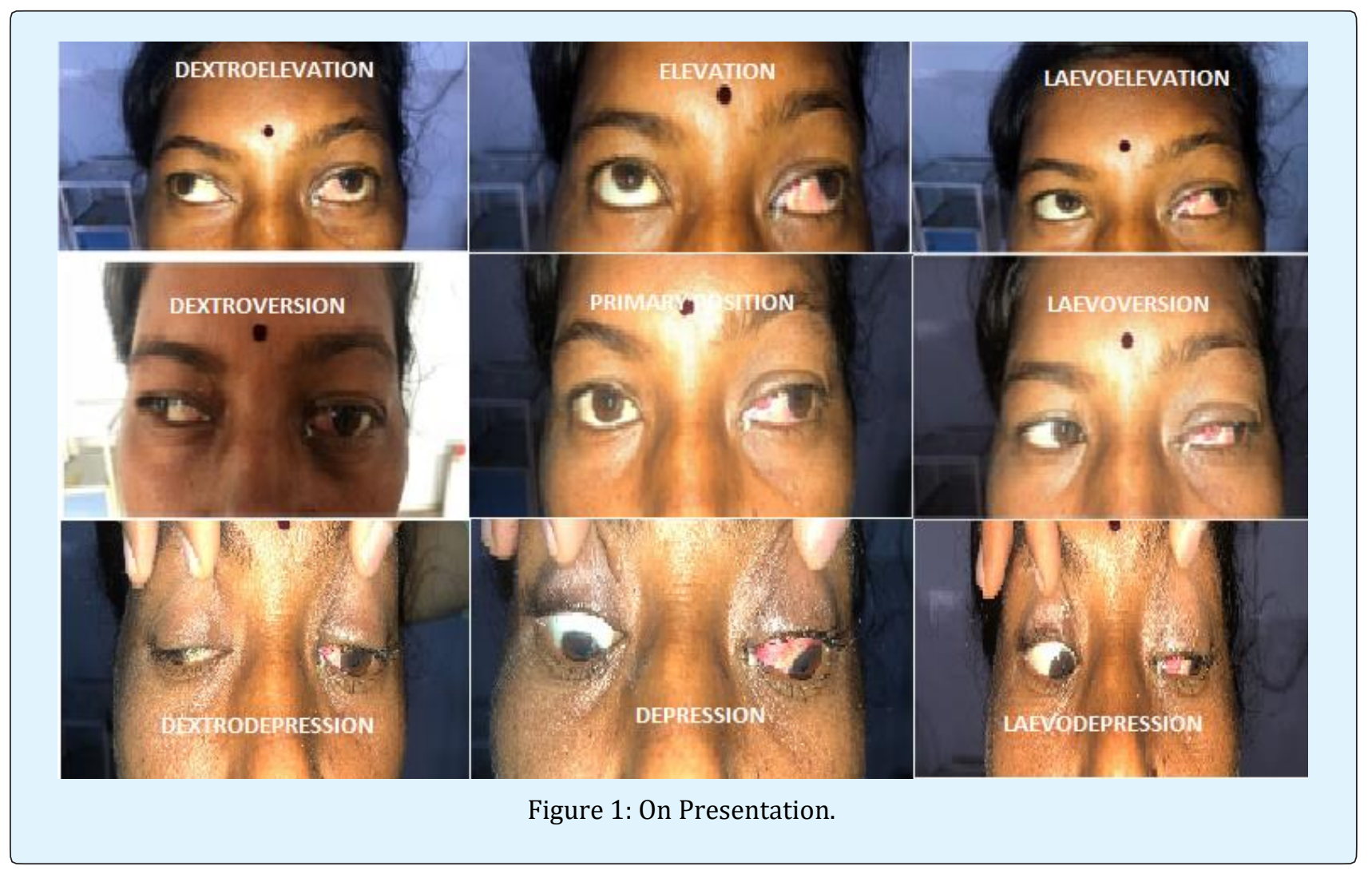



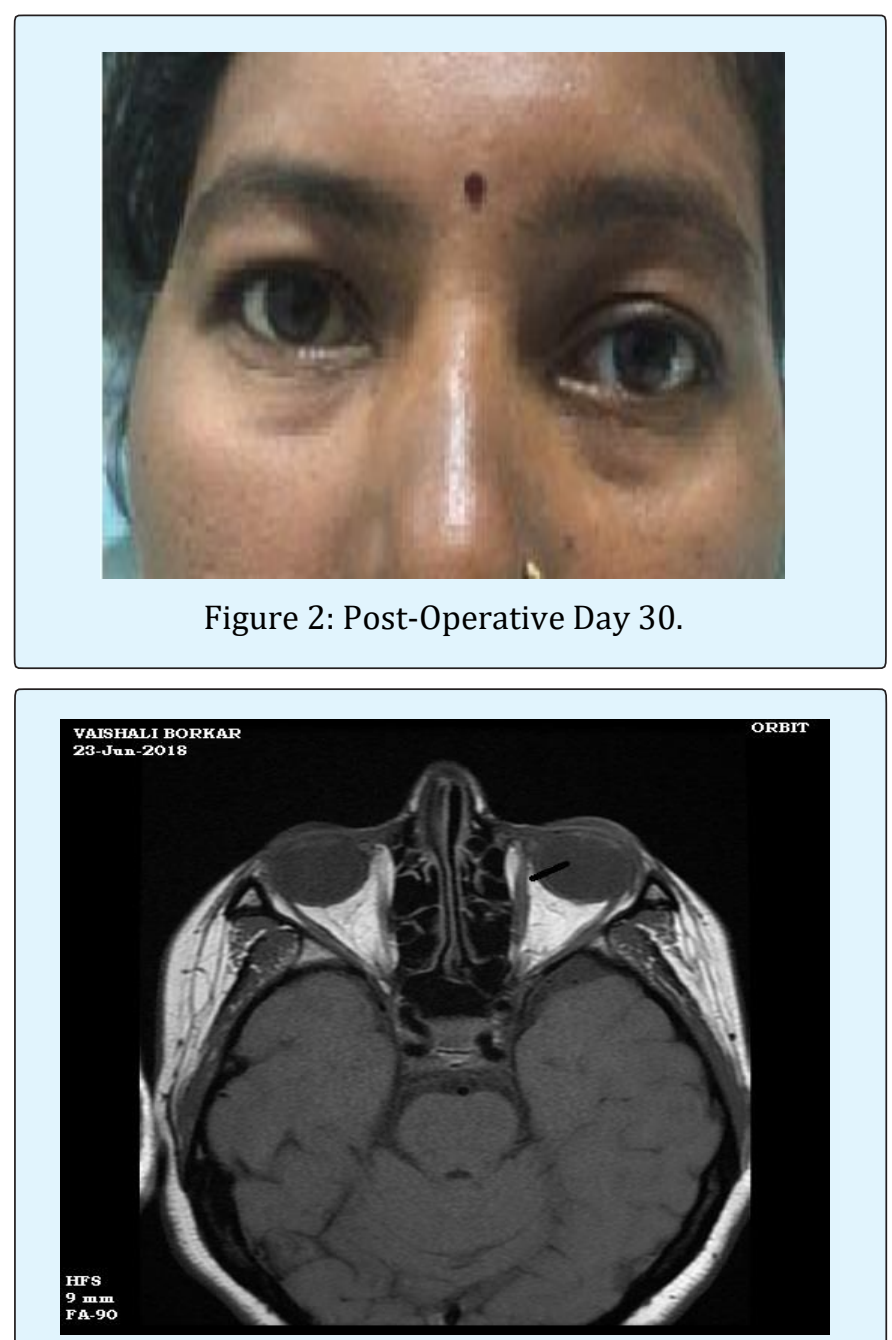

Figure 3: MRI (T2): showing hyperintense medial rectus belly.

\section{Discussion}

Blunt ocular injuries often involve extraocular muscles. In such injuries, the muscle tendon or the muscle may be torn across completely or partially. Complete disinsertion of a muscle may lead to retraction, making it difficult to find the muscle. The medial rectus muscle may be injured alone or along with other muscles.

In the present case, only the medial rectus was involved which was partially dehiscent. It was easily identified and successfully sutured with good outcome.Accurate diagnosis and prompt intervention resulted in good surgical outcome. Optimal intervention generally involves an initial attempt at targeted exploration with attempted recovery and/or repair of the damaged, transected, or lost extraocular muscle which may be performed early, immediately following the injury [1-3].

\section{Declaration}

The authors certify that they have obtained all appropriate patient consent forms. In the form, patient has given his/her consent for his/her images and other clinical information to be reported in the journal. The patients understand that their names and initials will not be published and due efforts will be taken to conceal their identity, but anonymity cannot be guaranteed.

\section{References}

1. Lemade PT, Karandikar SC, Vaijwade SP, Ahuja S (1981) Traumatic disinsertion of medial rectus muscle. Indian J Ophthalmol 29(2): 115-116.

2. Murray AD (2015) An approach to some aspects of strabismus from ocular and orbital trauma. Middle East Afr J Ophthalmol 22(3): 312-319.

3. Choudhury D, Sharma PK (2016) A case report of traumatic dislocation of eyeball. Niger J Ophthalmol 24(2): 89-91. 